\title{
Should all GPs become NHS employees?
}

Independent contractor status creates unnecessary stress, writes Azeem Majeed, but Laurence Buckman values his autonomy and distance from a non-benign employer

\author{
Azeem Majeed professor of primary care ${ }^{1}$, Laurence Buckman GP partner ${ }^{2}$ \\ ${ }^{1}$ Department of Primary Care and Public Health, Imperial College London, London W6 8RP, UK; ${ }^{2}$ Temple Fortune Medical Group, London NW11 \\ 7TE, UK
}

\section{Yes-Azeem Majeed}

It's time that NHS general practitioners became NHS employees to end the anomaly that left GPs and their staff independently employed when the NHS was created in 1948.

Currently, two main types of GPs work in the NHS: independent contractors (GP partners) and salaried employees. An increasing proportion of GPs are salaried employees rather than self employed independent contractors: about 28\% (10 063/35 586) of GPs in England were salaried in 2015 compared with just $4 \%$ in 2002 (1085/29 202). ${ }^{2}{ }^{3}$ However, salaried GPs are rarely employed by the NHS; generally, they are employed by other GPs or commercial companies.

A recent survey of 573 GP partners by Pulse magazine found that $51 \%$ would become salaried for the right deal. ${ }^{4}$ The employment contracts of salaried GPs vary hugely, and they often have worse terms than doctors employed by the NHS-for example, less maternity leave or sick leave provision. Salaried GPs would therefore benefit from a transfer to NHS employment contracts, as would GPs who are currently self employed.

\section{Most stressed}

Primary care in England's NHS is in crisis. ${ }^{5}$ Recruitment of GPs is difficult throughout England, with many practices reporting vacant posts; many GPs are considering retiring early, and others want to cut down on their clinical work. ${ }^{7}$

In a survey of primary care carried out by the Commonwealth Fund in 11 countries GPs in the UK were the most stressed. ${ }^{8}$ UK GPs also reported high levels of dissatisfaction with their style of work-for example, the short consultation lengths and high number of patient consultations a day in the UK (92\% of GP consultations in the UK were less than 15 minutes compared with just $27 \%$ in the other 10 countries). ${ }^{8}$ Our current model of primary care is failing, and we will see a gradual implosion of general practice in many parts of England, notwithstanding the recent recognition of this problem by NHS England and the promise of increased investment in the NHS Five Year Forward View. ${ }^{9}$
The problems faced by GPs are partly due to the contracts that general practices have to provide NHS services and the way secondary care is organised. These contracts encourage the NHS to transfer work to primary care with the expectation that GPs will pick up this work at little or no extra cost. Most GPs would have no problem with taking on such work if they were given time to deal with it during their current working week. If GPs had employment contracts similar to NHS consultants they could have job plans, with time allocated for clinical work and for activities such as administration, teaching, training, and research.

\section{Better career structure}

Furthermore, because they would be working in organisations that employ many GPs, we could develop a better career structure. For example, it may be possible to create posts for GPs who specialise in the care of elderly people or in child health and for GPs who take on clinical leadership, quality improvement, and NHS management roles. ${ }^{10}$

As NHS employees, GPs would lose many of the responsibilities that make their work stressful. They would no longer be personally liable for meeting the requirements of the Care Quality Commission, ${ }^{11}$ and their hours of work would be protected by the European Working Time Directive. Any time spent working at evenings or weekends as part of extended hours schemes would have to be part of their contracted hours rather than in addition to their current work.

As employees, GPs would also no longer be the target of criticism from politicians, managers, the media, or the public when waiting times to see GPs increased or for not offering patients with complex health needs sufficient time. The NHS, as the employer, would be responsible for ensuring there were enough GPs to meet the demand for primary care and to address people's clinical needs. 


\section{No-Laurence Buckman}

Every year since the NHS was formed in 1948 someone has suggested that the UK's family doctors (GPs) should become NHS employees. Although many GPs choose to be salaried or to work as locums, a steadily shrinking majority still prefer to run their own practices as subcontractors to the NHS. There is little evidence to inform this debate because few countries have such well established primary care systems and fewer still have salaried family doctors. Those who want to change the status quo have not shown the advantages.

The hospital junior doctors' dispute with the English NHS regime provides a graphic demonstration of why GPs are much better off in semi-autonomous businesses, working for their patients in their own practices. Although government can impose whatever it likes on any part of the health service, it is far harder to impose something on professionals who are more distant from direct NHS employment. GPs' hard won freedoms have been progressively curtailed by bureaucracy, but the changes would probably have been greater if they had been directly employed by the NHS rather than being independent contractors.

What is clear is that an employed service will cost more and be less efficient than the independent one. Sick pay costs will rise and working patterns will change, possibly resulting in reduced patient access as GPs limit how hard they work in the employed setting.

\section{Unsurpassed autonomy}

Sessional or salaried GPs usually work for independent employers (whether NHS subcontractors, independent contractor GPs, or private companies) because of the relative freedom from interference that this offers them and their employers. Many independent GP contractors enjoy their status even in these dog days for the NHS. If they did not, they would leave or become sessional employees. Indeed, in a recent survey of 573 GP partners, $36 \%$ said that they would not consider becoming salaried. ${ }^{4}$

GP partners have the freedom to run their practices as they wish-as long as they deliver a safe and effective service; to choose who works with and for them; and to operate from premises that they control and for which they are locally accountable. Few employees have this much autonomy or such ability to innovate.

If all GPs became NHS employees, they may well have to work to tougher performance indicators with less cover (as we have seen with hospital and district nursing colleagues) and with whomever the NHS decides. Because GPs would have less incentive to control costs such a move could cost the NHS rather than save money. The only solution then would be a drop in GP pay.

The stability of general practice is largely down to the GP owned nature of the business and premises-a workforce will always act to deliver the best service if it has shares in that service. Ownership of premises is becoming less attractive for many as property prices exceed the reach of younger GPs and profits fall for older ones. But even renting your place of work gives you more control over your working environment than being placed in a clinical setting of an employer's choosing.

The greatest benefit for independent contractors, however, is the ability to make agreements with patients without the need for anyone else's approval. All doctors value their relationships with their patients, but employed doctors always have someone that they answer to (whether clinical or managerial) who is monitoring their activity and outputs. GPs are on a slightly longer leash, in time and distance, and can be more fearless advocates for their patients. If an independent GP and a patient agree on a course of action the response can be immediate, at least for the $84 \%$ of contacts that are resolved by GPs without recourse to other parts of the NHS. Even with multiple layers of regulation of the GP, the patient benefits faster and with more ease. Good care is encouraged when GPs personally depend on patients' satisfaction.

\section{Vulnerability to government whim}

Although employees have some protected rights and privileges that are not available to self employed GPs, these can be taken away at a moment's notice by a regime that cannot be trusted. How many GPs wish to place their entire income at the mercy of a corporate health service that seems not to care about its staff, the pressure under which they work, or their health or safety? We have seen several health secretaries pay lip service to GPs' efforts while piling on (unfunded) workload and bureaucracy; district nursing services have been allowed to wither to the current point of uselessness; staffing has been "modernised" with cheaper, less well trained staff; private businesses have taken over general practices only to fail themselves. GPs are now supposed to be offering routine care round the clock with a shrinking workforce and no recruits- this looks like reckless lack of care to me.

Despite the steady erosion of taxation benefits over the past 20 years, and even with the reducing benefit of property ownership, it remains economically beneficial to be part of an NHS independent contractor practice because it is possible to partially contain the economic damage of incessant "reform" on the business.

How many independent GPs would have preferred to have been in the position of our junior colleagues over recent months? I decide the rights that I have, as long as I deliver to my patients. No one can take that away while I employ myself.

Competing interests: Both authors have read and understood BMJ policy on declaration of interests and declare the following interests: AM is a GP principal and LB was chair of the BMA's GP committee from 2007 to 2013.

Provenance and peer review: Commissioned; externally peer reviewed.

1 Jones R, Majeed A, Bhatti N, Murchie P, Vautrey R, Rosen R. Should general practice give up the independent contractor status?Br J Gen Pract 2015;65:314-6. doi:10.3399/ bjgp15X685441 pmid:26009525.

2 Health and Social Care Information Centre. General and personal medical services England 2002-2012. 2013. http://www.hscic.gov.uk/catalogue/PUB09536

3 Health and Social Care Information Centre. General and personal medical services, England 2005-2015. 2016. http://www.hscic.gov.uk/catalogue/PUB20503

4 Lind S. Over half of GP partners would go salaried "if offered the right deal." Pulse 2016 Jun 27. http://www.pulsetoday.co.uk/your-practice/practice-topics/employment/over-halfof-gp-partners-willing-to-go-salaried/20032143. article

5 Majeed A. Primary care: a fading jewel in the NHS crown. London J Prim Care (Abingdon) 2015;7:89-91. doi:10.1080/17571472.2015.1082343 pmid:26681980

6 Wilkie V, Ralphs A. The pressures on general practice. BMJ2016;353:i2580. doi:10.1136/ bmj.i2580 pmid:27169432.

7 King's Fund. Understanding the pressures in general practice. 2016. http://www.kingsfund. org.uk/publications/pressures-in-general-practice

8 Martin S, Davies E, Gershlick B. Under pressure. What the Commonwealth Fund's 2015 international survey of general practitioners means for the UK. Health Foundation, 2016. http://www.health.org.uk/publication/under-pressure

9 Everington S, Roland M. NHS England provides a major boost for general practice. BMJ 2016;353:i2357. doi:10.1136/bmj.i2357 pmid:27117454

$10 \mathrm{Ham} \mathrm{C.} \mathrm{Making} \mathrm{general} \mathrm{practice} \mathrm{fit} \mathrm{for} \mathrm{the} \mathrm{future.} \mathrm{2014.} \mathrm{http://www.kingsfund.org.uk/blog/}$ 2014/02/making-general-practice-fit-future

11 Matthews-King A. New look CQC inspections will be "stressful and expensive." Pulse 2014 Apr 30. http://www.pulsetoday.co.uk/your-practice/regulation/cqc/new-look-cqcinspections-will-be-stressful-and-expensive/20006589.fullarticle

Published by the BMJ Publishing Group Limited. For permission to use (where not already granted under a licence) please go to http://group.bmj.com/group/rights-licensing/ permissions 
